\title{
Erratum to: Spontaneous skin regression and predictors of skin regression in Thai scleroderma patients
}

\author{
Chingching Foocharoen • Ajanee Mahakkanukrauh • \\ Siraphop Suwannaroj • Ratanavadee Nanagara
}

Published online: 30 July 2011

(C) Clinical Rheumatology 2011

\section{Erratum to: Clin Rheumatol}

\section{DOI 10.1007/s10067-011-1744-z}

The minor change is in page 4, left column, line 30 . It should be "the 12-, 24-, 36-, and 48-month skin regression rate" not "48-year".

The online version of the original article can be found at http:// dx.doi.org/10.1007/s10067-011-1744-z.

C. Foocharoen $(\bowtie) \cdot$ A. Mahakkanukrauh $\cdot$ S. Suwannaroj ·

R. Nanagara

Division of Allergy-Immunology-Rheumatology,

Department of Medicine, Faculty of Medicine,

Khon Kaen University,

Khon Kaen 40002, Thailand

e-mail: fching@kku.ac.th 